\title{
The Chain Dogfish, Scyliorhinus retifer (Garman, 1881), New to the Canadian Atlantic Ichthyofauna
}

\author{
Gilhen, John ${ }^{1},{\text { Brian W. } \text { COAD }^{2} \text { and Andrew Hebda }}^{1}$ \\ ${ }^{1}$ Nova Scotia Museum of Natural History, 1747 Summer Street, Halifax, Nova Scotia B3H 3A6 Canada \\ ${ }^{2}$ Canadian Museum of Nature, P.O. Box 3443, Station D, Ottawa K1P 6P4 Canada
}

Gilhen, John, Brian W. Coad, and Andrew Hebda. 2003. The Chain Dogfish, Scyliorhinus retifer (Garman, 1881), New to the Canadian Atlantic Ichthyofauna. Canadian Field- Naturalist 117(3): 475-477.

The Chain Dogfish, Scyliorhinus retifer, is known from southwestern Georges Bank in the United States but until now there have been no verifiable records of this shark in Canadian waters. We report on two specimens Georges Bank, Big LaHave Bank, Nova Scotia, that represent the first and second records for the Canadian Atlantic.

Key Words: Chain Dogfish, Scyliorhinus retifer, first records, Canadian Atlantic.

The Chain Dogfish, Scyliorhinus retifer, is a member of the Cat Shark Family (Scyliorhinidae) found from the United States south to Nicaragua. It is distinguished from its Atlantic coast relatives by having crests over the eyes and by a chain or net body pattern. There has been no confirmed record for Canadian waters although Coad et al. (1995) report it from southwestern Georges Bank in American waters based on Bigelow et al. (1953). This paper reports the presence of this shark in Canadian waters based on two specimens from Nova Scotia.

\section{Methods and Materials}

Counts and measurements follow Hubbs and Lagler (1964) and Springer (1979). Abbreviations are TL = total length; NSM = Nova Scotia Museum of Natural History, Halifax. NSM85357, female, $37.5 \mathrm{~cm}$ TL, 253.7 g, Nova Scotia, Georges Bank, 1980s (kept on ice for seven days in a display at the Lunenburg Fisheries Exhibition in Lunenburg, Nova Scotia; captured by the Canadian scallop fishery). NSM85352, female, $38.6 \mathrm{~cm}$ TL, $219.7 \mathrm{~g}$, Nova Scotia, southern outer edge of Big LaHave Bank, $42^{\circ} 32^{\prime} 00^{\prime \prime} \mathrm{N}, 64^{\circ} 32^{\prime} 00^{\prime \prime} \mathrm{W}$, captured with Silver Hake, Merluccius bilinearis, in an otter trawl between 140 and 200 fathoms, 10 May 2001, David A. D'Eon (Captain of the trawler Seamans Toy out of Lower West Pubnico).

\section{Results}

The body is slender with a wedge-shaped snout, although the belly may be distended with food. The nasal flaps do not reach the edge of the upper lip. Crests are present over the eyes. Teeth are triangular, smooth and have a long central cusp with a smaller cusp on each side. Denticles on the flank are small, lanceolate and flat.

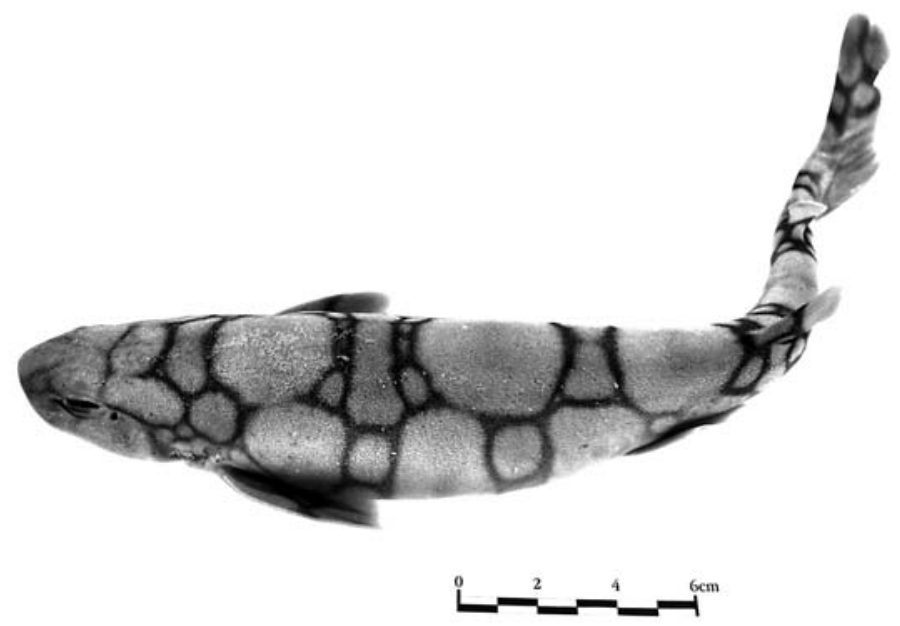

FIGURE 1. An adult female Chain Dogfish, Scyliorhinus retifer, first record for the Canadian Atlantic, captured on Georges Bank, Nova Scotia, in the 1980s (Nova Scotia Museum of Natural History Negative Number N-25,643). 



FIGURE 2. An adult female Chain Dogfish, Scyliorhinus retifer, second record for the Canadian Atlantic, captured at the southern outer edge of Big LaHave Bank, Nova Scotia, 10 May 2001, by David A. D'Eon (Nova Scotia Museum of Natural History Negative Number N-25,642).

Measurements after Springer (1979) for the two specimens are as follows in percentages of total length: tip of snout to front of mouth 4.8-4.9; to eye 6.4-6.7; to first gill slit 15.4-15.5; to fifth gill slit 19.0-19.9; to origin of pectoral fin 18.3-19.6; to origin of first dorsal fin 51.5-52.5; to origin of pelvic fin 43.2-44.6; to second dorsal fin 67.0-69.0; to anal fin 61.5-63.1; to origin of upper caudal fin lobe 77.5-78.7; to anterior end of cloacal opening 45.3-47.2. Orbit diameter 3.83.9 and orbit height 0.9-1.0. Least distance between nasal apertures 1.7. Mouth width 8.0-8.2 and mouth length 4.0-5.0. Length lower labial furrow 1.4. Height of first gill slit 1.8-2.0 and height of fifth gill slit 0.71.1. First dorsal fin base length 6.0-6.7 and anterior margin length 9.9. Second dorsal fin base length 4.95.6 and anterior margin length 7.3-7.7. Anal fin base length 6.5-7.6 and anterior margin length 7.4-7.6. Length outer margin of pectoral fin 13.2-14.1. Distance between first and second dorsal fin bases 10.4-11.1.

The chain pattern of narrow black lines forming 7 (7-8 in the literature) dorsal saddles is distinctive and is illustrated in Figures 1 and 2. In preservative NSM85352 is grey with black chain markings while NSM85357 is brown with dark brown chain markings.

\section{Discussion}

The two specimens agree generally with the description of this species in Springer (1979) and Springer and Sadowsky (1970), being females of the subspecies $S$. retifer retifer. This subspecies reaches a maximum size of over $52.0 \mathrm{~cm}$ in females. Females may mature at $38.0 \mathrm{~cm}$, perhaps larger. Males are mature at about $30.0-50.0 \mathrm{~cm}$. Northern populations may mature at a smaller size than southern ones, and one of these Canadian specimens was approaching maturity (NSM85357 has eggs about $1.2 \mathrm{~cm}$ in diameter). This species inhabits rough bottoms, not easily trawled, as well as smooth bottoms, from $58 \mathrm{~m}$ to $550 \mathrm{~m}$ on the continental shelf and upper slope. Some were associated with anemones. Water temperatures are $8.5-14.0^{\circ} \mathrm{C}$ and lower temperatures may limit its occurrence in Canada. Stomach contents include squids (NSM85357 contains a squid), fishes, worms and crustaceans. Some were reported to have pebbles in the stomach. There are 6-20 ova up to $1.8 \mathrm{~cm}$ in diameter in a single, left ovary. Egg cases, up to 6.3 by $2.7 \mathrm{~cm}$ with long tendrils, are deposited on hard substrates or attached to hydrozoans attached to such substrates (Springer and Sadowsky 1970; Springer 1979; Castro et al. 1988; Able and Flescher 1991; Coad et al. 1995).

\section{Acknowledgments}

We are grateful to Captain David A. D'Eon, Lower West Pubnico, Yarmouth County, Nova Scotia, who collected the second Chain Dogfish and donated it to the Nova Scotia Museum of Natural History. We thank Albert D'Entremont, science teacher, at Saint Anne du Ruisseau School, West Pubnico, who is an important liaison between the fishers of West Pubnico and the Nova Scotia Museum of Natural History. Over the years he has held in frozen storage many important marine specimens which he receives from local fishers, including our second Chain Dogfish (NSM85352), until they can be brought to the Nova Scotia Museum of Natural History to be identified, catalogued and preserved for future study.

The photographs, Figures 1 and 2, are by Roger Lloyd, Learning Resources and Technology, Nova Scotia Department of Education.

\section{Literature Cited}

Able, K. W., and D. Flescher. 1991. Distribution and habitat of chain dogfish, Scyliorhinus retifer, in the mid-Atlantic Bight. Copeia 1991: 231-234.

Bigelow, H. B., W. C. Schroeder, and S. Springer. 1953. New and little known sharks from the Atlantic and from the Gulf of Mexico. Bulletin of the Museum of Comparative Zoology 109(3): 213-276. 
Castro, J. I., P. M. Bubucis, and N. A. Overstrom. 1988. The reproductive biology of the chain dogfish, Scyliorhinus retifer. Copeia 1988: 740-746.

Coad, Brian W., H. Waszczuk, and I. Labignan. 1995. Encyclopedia of Canadian Fishes. Canadian Museum of Nature, Ottawa, and Canadian Sportfishing Productions, Waterdown, Ontario. viii +928 pages

Hubbs, C. L., and K. F. Lagler. 1964. Fishes of the Great Lakes Region. The University of Michigan Press, Ann Arbor. $\mathrm{xv}+213$ pages
Springer, S. 1979. A revision of the catsharks, Family Scyliorhinidae. NOAA (National Oceanographic and Atmospheric Administration, NMFS (National Marine Fisheries Service) Circular 422: v +152 pages

Springer, S., and V. Sadowsky. 1970. Subspecies of the western Atlantic cat shark, Scyliorhinus retifer. Proceedings of the Biological Society of Washington 83: 83-98.

Received 31 August 2001

Accepted 2 January 2004

\title{
First Record of Mink Frog, Rana septentrionalis, from Insular Newfoundland
}

\author{
Ian G. Warkentin ${ }^{1}$, Christine E. Campbell ${ }^{1}$, Kristin G. Powell ${ }^{1,2}$ and Tina D. LeOnard ${ }^{1,2}$ \\ ${ }^{1}$ Environmental Science, Sir Wilfred Grenfell College, Memorial University of Newfoundland Corner Brook Newfoundland \\ A2H 6P9 Canada \\ ${ }^{2}$ Department of Biology, Acadia University, Wolfville Nova Scotia B4P 2R6 Canada
}

Warkentin, Ian G., Christine E. Campbell, Kristin G. Powell, and Tina D. Leonard. 2003. First record of the Mink Frog (Rana septentrionalis) from insular Newfoundland. Canadian Field-Naturalist, 117(3): 477-478.

Two populations of the Mink Frog (Rana septentrionalis) were identified near Corner Brook Newfoundland during wider surveys for anurans on the west coast of the island. This brings to six the number of anuran species which are known to have been introduced to insular Newfoundland, with four known to be currently extant.

Key Words: Mink Frog, Rana septentrionalis, Newfoundland, introduced species.

The anuran fauna of insular Newfoundland is the result of intentional human introductions. The Green Frog (Rana clamitans) arrived about 150 years ago through its presumed accidental transport in shipments of hay from Nova Scotia to the St. John's area (Maret 1867; Johansen 1926). Between 1960 and 1966, Buckle (1971) systematically introduced the Northern Leopard Frog (Rana. pipiens), Wood Frog (R. sylvatica), Chorus Frog (Pseudacris triseriata) and American Toad (Bufo americanus) to various locations in western Newfoundland. These anuran populations have since undergone extensive change. Both the Northern Leopard Frog and Chorus Frog apparently have disappeared (Maunder 1997), but populations of the other three species are now well established and are expanding throughout the western portion of the island (Maunder 1997; Powell 2002). The Green Frog remains the sole occupant of eastern portions of the island (Maunder 1997). Here we report the discovery on the west coast of the island of another introduced anuran, the Mink Frog (Rana. septentrionalis).

Field work was conducted in summer 2001 to assess the distribution of anuran populations in three regions along the west coast of Newfoundland - the Codroy Valley in the southwestern corner of the island, the Deer Lake-Stephenville region in west central Newfoundland, and Gros Morne National Park on the west coast of the island at the base of the Great Northern Peninsula. American Toads were heard at numerous locations in all three regions, Wood Frogs were heard throughout the Deer Lake-Stephenville region, while
Green Frogs were heard throughout the Deer LakeStephenville and Codroy Valley regions and at one location in Gros Morne National Park (Powell 2002). We encountered Mink Frogs at one site in the Deer Lake-Stephenville region. Located along the Ring Road of Corner Brook, $4.8 \mathrm{~km}$ west of the Trans Canada Highway $\left(48^{\circ} 55.61^{\prime} \mathrm{N}, 57^{\circ} 57.11^{\prime} \mathrm{W}\right.$; all positions determined using a Garmin ${ }^{\circledR}$ GPS model 12 XL, Olathe Kansas, USA), the site consists of a shallow pond approximately $60 \mathrm{~m}$ long by $10 \mathrm{~m}$ at its widest point. The presence of the frogs was initially detected during daylight hours on 30 May 2001 and on a return visit later that day in excess of 30 Mink Frogs were counted in a $10 \mathrm{~m}^{2}$ area on one end of the pond. Additionally, Powell (2002) found 25 Mink Frog tadpoles along a 10-m stretch of pond shoreline at this site on 30 June 2001. Although Mink Frog adults are considered by some to strongly resemble the appearance of Green Frogs at the northern end of their range (Conant and Collins 1991), there are several distinctive features of $R$. septentrionalis including the mink-like smell, spotting pattern on the legs, the extent of dorsolateral ridges, and the extreme webbing on the toes of the hind feet (Schueler 1975; Conant and Collins 1991). In combination, these characteristics enabled us to distinguish Mink Frog adults from morphologically similar Green Frogs. Voucher specimens were collected and deposited at the Provincial Museum of Newfoundland and Labrador in St. John's, Newfoundland (Provincial Museum catalogue numbers NFM HE-119 and NFM HE-120). Species identification was confirmed through night- 